\title{
Experiência literária e experiência urbana: notas sobre a literatura marginal
}

\author{
Lucas Amaral de Oliveira*
}

\section{Introdução}

Foi a propósito dos estudos culturais e literários mais recentes que se colocou, para mim, a questão da cultura periférica enquanto sistema relativamente autônomo de criações e práticas de grupos marginalizados que, com pretextos, incentivos e estratégias variadas, negam o estado de coisas predominante, utilizando a produção artística como aparato de empoderamento e inclusão. Por cultura periférica entendo um tipo de cultura emergente produzida e difundida nas periferias e que, especialmente nos últimos anos, tem sintetizado a abertura de novos canais de comunicação e novas formas de significação para as produções, materiais e imateriais, nas margens urbanas, contemplando, com isso, diferentes experiências, saberes, imaginários, estéticas e sentidos na construção de uma cultura mais próxima à realidade de bairros populares.

Nesse contexto, críticos contemporâneos têm polemizado, de forma incisiva, a respeito de produções literárias que estão apartadas dos espaços dominantes de consagração, prestígio e poder, com o propósito de saber se, e em que medida, a estética marginal é legatária de tradições diversas e beneficiária de influências passadas (Dalcastagnè, 2007; Eslava, 2004; Faria, 2011; Oliveira, 2016; PatrocíNIO, 2012; TeIXeIro, 2013; TenNinA, 2017). Em função dessa rica agenda de pesquisa, observa-se ainda a tentativa de pesquisadores de convergir esforços de pesquisa na busca de uma substância, de um sentido próprio e de efeitos culturais peculiares e duradouros desse conjunto de criações e estilos do fazer literário (BIN, 2009; Faria; Penna, 2015; Leite, 2014; NAscimento, 2009; 2011; Reyes, 2013; SALOM, 2014; SILVA, 2012).

Porém, parece fugir a tal fortuna crítica um zelo maior em "especializar" as modalidades de sua manifestação. As obras, as criações poéticas e as intervenções performáticas nos saraus, por exemplo, corolários do movimento da literatura marginal, são produtos e produtoras de processos no interior dos quais experiências urbanas e literárias emergem como que forjadas por relações que ganham forma

Doutorando do Programa de Pós-Graduação em Sociologia da Universidade de São Paulo (USP), São Paulo, SP, Brasil. E-mail: lucas_amaral_oliveira@hotmail.com 
em certos espaços da cidade. Nessa medida, gostaria aqui de perscrutar e dialogar com a cultura periférica, mais especificamente com a literatura marginal e suas expressividades, por meio da lente do espaço. Trata-se de desvendar como a categoria espaço é abordada dentro da proposta da literatura marginal paulistana.

O propósito deste texto, portanto, é flagrar o impacto de experiências urbanas variadas no labor literário, nas estratégias de atuação e na produção textual e poética mais recente de escritores das periferias urbanas - vale dizer, de bairros com pouco acesso a políticas públicas voltadas às artes e com distribuição precária de equipamentos, bens e serviços culturais. O ponto de partida é problematizar, de acordo com as evidências que me foram postas pela pesquisa, em que medida se pode atrelar criação textual, representação do espaço e participação artísticocomunitária dentro desse fenômeno cultural ainda em curso.

\section{A literatura marginal e a influência da cultura hip-hop}

Os artistas do hip-hop, movimento que ganhou força em São Paulo entre o final dos anos 1980 e início dos 1990, foram os que primeiro produziram discursos que deram mais visibilidade às periferias urbanas, a partir do combate aos mecanismos de marginalização social e racismo. Isso foi significativo, pois logrou denunciar a violência contra os mais pobres, negros e periféricos, cunhou projetos sociais e pedagógicos voltados a jovens em situação de risco e propiciou que indivíduos considerados "marginais" se identificassem com os espaços urbanos que os circundavam, explorando, proativamente, situações de exclusão e preconceito sócio-racial e, com efeito, ressignificando seus lugares de atuação.

Para além disso, a cultura hip-hop em São Paulo foi capaz de formatar uma linguagem própria (grafite e pixo, break, poesia, música, vestimenta, expressões idiomáticas, autoestima racial etc.) entre indivíduos que se reconheciam como periféricos. Ao mesmo tempo, esforçou-se por inserir seus produtos na indústria cultural e de consumo, sem perder, contudo, suas raízes. O rap, em especial, achou brechas em um mercado fechado para quem vivia em territórios segregados e estigmatizados, o que proporcionou às periferias vias de inserção no sistema econômico e social, mediante a vinculação de conteúdos localmente produzidos no campo artístico mais global. Para Lourdes Carril (2006), justamente nesse período despontou uma forma autêntica e inédita de comunicação artístico-musical, do "pensar o mundo" com base na experiência e na ressignificação de uma história até então excluída das narrativas oficiais.

Inclusive, o princípio do "pensar o mundo", discurso muito recorrente no rap, está próximo do quinto elemento do hip-hop, o conhecimento, que foi acrescentado, em meados dos anos 1980, aos quatro elementos básicos existentes (SILVA, 
2012, p. 33). ${ }^{1}$ Trata-se de algo que perpassa todos os outros princípios constituintes, como linha que os costura em uma única estrutura simbólica: conhecimento que é crítico do mundo, da cultura, do mercado, dos valores que um agrupamento suporta e reproduz; conhecimento que é essencial para a formação identitária, étnica e racial de certo grupo, principalmente em um contexto populacional negro, pobre e periférico.

Assim, acredito que uma das maiores realizações do hip-hop foi o cultivo de uma atitude, de um saber e de uma autoestima de naturezas sociais e espaciais; afinal, foi por meio desse cultivo que tais reconfigurações de autoestima reformularam perspectivas coletivas sobre o local, em especial na forma de orgulho do bairro de origem, da periferia, de ser e afirmar-se enquanto marginal ou periférico. Basta ouvir uma letra de rap qualquer para notar a relevância dos bairros/distritos/localidade para a poética das canções e rimas, como "Pirituba Parte II", de RZO, "No Brooklin", de Sabotage, e "Salve", dos Racionais MC's. Ou, então, um dos primeiros nomes no rap paulista, $\mathrm{MC}$ Ndee Naldinho, figura importante nos primórdios do hip-hop, na década de 1980, que, em sua música chamada "A Voz do Gueto", diz o seguinte:

[O rap] troca uma ideia através da música

Ele denuncia a injustiça que o meu povo vive

Ele conta a vida do crime,

ele fala de violência

[...] É a ideia quente do malandro de atitude

É voz do gueto, dos muleke, das mina

Do povo da periferia

O som da favela, dos loco, dos preto [...].

E eu sou periferia, a voz do gueto

O som da favela, dos loco, dos preto. ${ }^{2}$

Como afirma o escritor Rodrigo Ciríaco (apud Tennina et al., 2015, p. 350), quando reflete sobre as proximidades e influências entre as formas de cultura expressiva do rap e da literatura marginal, "o poeta do sarau é uma espécie de MC", e segue dizendo que a própria literatura marginal "entra, inclusive, no que a gente

1 Segundo pesquisa de Rogério de Souza Silva, no final dos anos 1970, o DJ Afrika Bambaataa, visando estruturar o hip-hop enquanto movimento, estabeleceu seus quatro pilares: "o DJ (discjockey), responsável pelas batidas para o cantor rimar; o MC (master of ceremony) ou rapper, caracterizado por uma maneira de cantar marcada por frases longas e rimadas - seu estilo musical recebe o nome de rap (rhythm and poetry); o Break, dança executada pelo b.boy (dançarino); e o Grafitti, expressão visual cujo foco é a pintura de muros e prédios. Essas se tornam características essenciais do hip hop". Depois, um quinto elementos foi integrado, o "conhecimento", saber que integra os anteriores no contexto da cultura periférica, politizando todas as dimensões dessa produção estética.

2 Letra disponível em: <https://www.letras.mus.br/ndee-naldinho/1115639/>. Acesso em: 10 abr. 2018. Ndee, junto com outros nomes, como Thaíde, Nelson Triunfo, RZO e Racionais MC's, foi uma figura importante nos primórdios do hip-hop e na organização de encontros na região de São Bento, São Paulo, em meados da década de 1980. 
pode chamar de quinto elemento, que é o conhecimento, né? [...] Dentro desse quinto elemento do conhecimento é onde entra a literatura também. Então, eu não consigo dissociar uma coisa da outra". Sérgio Vaz segue o mesmo caminho explicativo, quando diz, em entrevista concedida a Ingrid Hapke:

São duas fases. A periferia passou uma fase muito bacana, que foi a [...] do hip hop. Quando o hip hop chegou na periferia dizendo: "nós somos negros, nós somos da periferia”, as pessoas começaram a falar: "opa, mas peraí, eu também sou, também sou, também sou!”. Depois de alguns anos, a literatura deu o choque cultural que faltava. [...] E eu acho que a literatura, quando chegou, deu um ato mais político; ela entregou conhecimento, saber. [...] Acho que a periferia [...] começou a se interessar por voltar a estudar, por entrar na faculdade, por fazer mestrado [...] por editar livros. Então, acho que primeiro veio a força, e atrás dela veio a política. Acho que primeiro veio a prática, depois veio a teoria. E essas duas coisas se fundiram (TenNinA et al., 2015, p. 288).

O poeta demarca a importância da cultura hip-hop na formação da literatura marginal, ressaltando um suposto processo de politização e aquisição de conhecimento crítico por parte de moradores da periferia, o que desaguou em uma formação literária muito próxima, ainda que independente, da poética do rap. Para Drix Solinas, outra personalidade importante do movimento marginal paulistano, integrante do Coletivo Sarau da Ademar:

[...] o hip hop tem um papel fundamental nisso tudo, ele é a trilha sonora dos saraus [...] E o rap é ritmo e poesia [...]. Na verdade, é literatura também. E eu acho que foi muito importante o encontro do hip hop com a literatura da periferia, porque eles se complementam. Um movimento complementa o outro e um ajuda o outro. Então, [agora] você tem os grupos de hip hop frequentando o sarau, e você tem poetas fazendo intervenções nos shows de hip hop (apud TenNinA et al., 2015, p. 349-350).

O escritor e rapper Dugueto Shabazz (2006, p. 15), quando explica seu labor literário, diz o seguinte: "[a literatura marginal] é a versão escrita dessa gambiarra que nós chamamos de música, que faz coro a bandidos, incita a tensão racial e põe o submundo em evidência. Dessas páginas, voam tiros e rasgam scratches. ${ }^{3}$ As questões periféricas agora são centrais, jugulares". A escrita que esses escritores propõem está em consonância com a dimensão sociopolítica consolidada pelo rap, tido como sua influência estética mais direta. Shabazz sugere, ainda, que a periferia está no centro das lutas atuais. Foi a partir dessa formatação difusa e heterotópica que o movimento literário passou a ter atuação "jugular" nas periferias

3 Scratch é uma técnica musical, inventada em 1978, pelo DJ Grandmaster Flash, um dos pioneiros da cultura hip-hop no mundo, usada para produzir sons ao "arranhar" o disco de vinil para frente e para trás, repetidas vezes. 
urbanas, sobretudo com o emprego do aparato literário como mecanismo de reflexão/representação crítica da realidade, usando a violência e as desigualdades de bairros populares como cenário e objeto de narrativas.

Há muitos textos, crônicas, poesias e intervenções performáticas que podem ser ouvidas nos saraus que exemplificam esse mecanismo e remetem às influências do rap nessa produção literária, bem como ao uso de estratégias de desestigmatização análogas àquelas usadas pela cultura hip-hop. Cito um excerto elucidativo, novamente do poeta Rodrigo Ciríaco:

O banquete está posto. A nossa santa ceia está servida. Livros expostos. Estende-se a mão, chamamos o nosso convidado. Para iniciar a partilha. Do pão. Da palavra. O pão-lavra. [...]. Alguém inicia: cê é da Paraíba? Talvez sim, talvez não. Todos somos. Mas sonegamos. Como só negamos raízes negras, indígenas, nordestinas que são resgatadas com maestria, no verso bem mesclado, no cordel, no coco embolado. Num repente chapado que alguém estranha: é rap? É. É raiz? Poesia (CiríACO, 2012, p. 92).

Tal como o hip-hop - também o cordel ${ }^{4}$ e a cultura negra, ${ }^{5}$ insinuado pelo escritor da zona leste -, a literatura marginal emerge das periferias e conserva vínculo especial e específico com o lugar de origem. É nele que se formatam as identidades de seus agentes, na medida em que ali se enuncia um espaço que é geográfico, mas também de afetividade, pertencimento, identificação; é um espaço que urge por ser valorado, ressignificado e positivado pelas estratégias de seus agentes. Tome como modelo o trecho do poema de Shabazz, "Aos flancos e barrancos", que propõe a releitura do termo "favela", ${ }^{6}$ para criticar sua estigmatização e reafirmar a periferia como território de "humildade e muita arte em prosa e verso":

4 A literatura de cordel também é uma grande influência estética, que ganhou importância em função das migrações para São Paulo. Registra-se o aparecimento dos primeiros livretos de cordel no Brasil, mais precisamente em Recife, na segunda metade do século XIX. Sobre isso, ver Queiroz (2005). A influência que a estética do cordel exerceu sobre os marginais pode ser notada em alguns poemas, como neste trecho de Augusto Cerqueira, que ouvi no Sarau do Binho: "Tô cansado di vê anjinho / lá na banca di jornal. / Mas com’eu num apito em nada, / nem na guerra nem no amô, / resorvi ixplorá um tikin / meus dote de rimadô / e formá um mundo novo / onde num reinasse a dô”. Augusto Cerqueira é um dos autores marginais que mais exploram essa forma literária hoje em dia.

5 Sobre a influência da cultura negra, ver a pesquisa de José Carlos Gomes da Silva (2013), que problematizou nexos culturais, políticos e estéticos responsáveis por conectar o passado e o presente na literatura afro-brasileira/negra e marginal. Sobre a mesma relação, ver a obra de Mário Augusto Medeiros da Silva (2013), na qual o sociólogo buscou contrapontos e semelhanças entre autores negros dos anos 1960 e 1970 e os marginais das décadas de 1990 e 2000.

6 Euclides da Cunha foi um dos primeiros a utilizar o termo "favela". Em Os Sertões (1902/1985), o termo tinha uma acepção geográfica, ao designar uma colina (Morro da Favela) ao sul de Canudos, onde era comum uma planta euforbiácea, conhecida por favela (faveleira, mandioca-brava). Trata-se de uma leguminosa, com espinhos e flores brancas dispostas em cimeiras (o fruto é semelhante às sementes de fava, o que originou o nome). Depois, o termo irá designar os morros ocupados na cidade do Rio de Janeiro, nas imediações da Central do Brasil. Isso, porque alguns dos soldados que lutaram em Canudos, ao regressarem para a capital de então, o Rio de Janeiro, e sem os estipêndios que lhes foram prometidos pelo governo republicano, instalaram-se em cons- 
Era uma vez uma planta chamada favela

Que só a via quem tinha coragem de ir perto dela

Porque ela só crescia em lugares difíceis

Onde hoje os homi sonha em fazer edifício.

Findada a escravidão, fundada por Providência

$\mathrm{Na}$ cidade maravilhosa, por excelência

Vieram soldados morar, e a tal fato aludo

Homens que receberam ordens de matar em Canudos

Alguns a chamam de mandioca brava

A maioria de favela, porque ela lembra uma fava.

[...] Alvo da polícia, renda das milícia

Sem coluna social, todo dia ela é noticia

O termo favela se tornou pejorativo

E por que comunidade? Ela é menos ofensiva?

Somos sociedade, somos capital ativo

E não bode expiatório do especulativo

Somos Dugueto [...] humildade e muita arte em prosa e verso.

[...] Pode ser em Trípoli, Bombaim ou Marrakesh

No centro de São Paulo, confuso igual Bangladesh

Pode ser no nordeste, casa de pau-a-pique

A cada esquina um bar, Zanzibar, Moçambique

Pode ser Cingapura, a de lá ou a daqui

Favela é ginga pura, da Jamaica ao Haiti

Minha saudação a todas, da lembrança nunca passa

Eu mando esse salve pro meu Morro da Fumaça. (ShABAzz, 2015a)

Então, se há violência, desigualdade, racismo, há seu contraponto, a criação poética e a potência cultural, a solidariedade e a coletividade entre moradores. Essa é a virada de jogo que, pela literatura, o movimento marginal realiza: a partir de um saber localizado, sua elaboração poética, explorar uma ressignificação do espaço periférico e do que nele está representado.

Acredito que a literatura seja um processo social que se inicia com a negociação de experiências variadas, com a seleção de convenções passadas e, a partir dessa base, com a invenção de novos estilos e propostas estéticas. Mas, vale perguntar, como o projeto estético marginal - fruto de uma atividade artística e de um labor literário que vêm sendo exercidos por agentes que, em sua maioria, são submetidos a processos de exclusão e marginalização aos quais eles se referem em suas obras - vem tentando lidar com o próprio espaço social de onde fala e escreve? E como, a despeito de uma série de constrangimentos de que se tem ciência, tal produção vem se preocupando com a releitura do cotidiano e a interpretação da experiência urbana, de modo a falar da, sobre e para a periferia? Gostaria de trabalhar, agora, essas questões, de modo a explicitar como a literatura marginal foi - e vem sendo - capaz de trazer para o centro de sua produção a própria margem, falando desde a margem e sobre a margem.

truções provisórias e sem infraestrutura no Morro da Providência. É a isso que Shabazz se refere em seu poema "Aos flancos e barrancos". 


\section{Textualizando a experiência urbana}

Creio que neste ponto seja conveniente uma delimitação sobre as alcunhas "marginal" ou "periférico", que tão regularmente são utilizadas pelos agentes literários em seus discursos. Documento publicizado pelo Fórum de Cultura da Zona Leste, "Pela Lei de Fomento à Periferia", que circulou entre os movimentos culturais e nas reuniões com o poder público local, durante os anos de 2014 e 2015, é revelador da visão que os agentes envolvidos têm de periferia:

Nós a compreendemos como espaço urbano geograficamente identificável, abrigo das classes trabalhadoras brasileiras, da maioria da população negra, indígenas urbanos e imigrantes, cujos traços culturais são entoados pela heterogeneidade resultante do encontro (nem sempre pacífico) dessa convivência multicultural atravessada pela desigualdade social. Periferia é [...] museu sem teto ou paredes, bolsões de expressões ancestrais, tradicionais, e experimentações inovadoras, cuja geografia é território, marca identitária e também espaço de exclusão econômica, com excesso de polícia e ausência de políticas públicas que procurem agir na resolução das consequências de um processo histórico de brutalidades sociais, desigualdades e injusta distribuição de riquezas. O termo Periferia convocado neste manifesto representa um ato político. Assumi-la como marca identitária significa evidenciar as disparidades sociais, econômicas, geográficas e culturais historicamente impostas. [...] Ainda que as periferias urbanas tenham características específicas entre si, a unidade está aí: relacionam-se com a questão urbana em posição de desvantagem política (Fórum de Cultura da Zona Leste, 2014). ${ }^{7}$

Em termos sociológicos, cada país ou região dispõe de categorias específicas para lidar com suas comunidades periféricas e mais estigmatizadas, isto é, para tratar dos espaços sociais localizados nas "margens" do sistema hierárquico de regiões geográficas que, forçosamente, compõem uma metrópole como São Paulo, nas quais os considerados "párias urbanos" residem, os problemas sociais se acumulam e onde a privação e o abandono parecem atrair "a atenção desigual e desproporcionadamente negativa da mídia, dos políticos e dos dirigentes do Estado" (WACQUANT, 2001, p. 2). Nesses espaços, acredita-se que o excesso de crime, violência, vício, miséria e desintegração social são marcas constituintes e quase indeléveis de sua natureza, cujas consequências diretas são a violência étnico-racial e a hostilidade em relação aos mais pobres.

Segundo o sociólogo Loïc Wacquant (2001), há algumas lógicas históricas e estruturais que abastecem essa nova configuração da marginalidade urbana ${ }^{8}: 0$ aumento da desigualdade no contexto do avanço econômico global nos últimos trinta

7 O texto pode ser lido na íntegra no blog Teatro de Rua e a Cidade, disponível em: <goo.gl/ $\mathrm{E}_{1} \mathrm{Ty}_{4} \mathrm{H}>$.

8 Oliven (2010, p. 34) lembra que o uso da categoria marginal nas ciências sociais precedeu o estudo da marginalidade na América Latina, cuja origem foi a publicação do artigo de Robert Park, 
anos; a chamada "dessocialização do trabalho assalariado", que vem acompanhada de uma degradação sistemática das condições básicas de emprego, remuneração e seguridade social; a redução das políticas de bem-estar social por parte dos Estados e de suas instituições (com regulamentações administrativas que falham em distribuir bens de subsistência básicos, como moradia, transporte, educação e complementos de renda); e uma concentração e sua consequente estigmatização espacial, o que mina laços de solidariedades locais e favorece a "racialização" de espaços urbanos periféricos.

Lourdes Carril (2006), por sua vez, indica um caminho alternativo para tratar das territorialidades periféricas ou marginais da cidade de São Paulo, a partir de uma dimensão que engloba, além de seu significado espacial, também sua conotação simbólica, composta de memórias, experiências, identidades, discursos e códigos que se movem pela cidade junto com seus agentes. E dessa forma é possível entender ao que se refere o poeta Binho (2013, p. 45), em um momento de intertextualidade com o Grande sertão: veredas, de Guimarães Rosa, quando diz que "a periferia está em toda parte, ou a periferia é dentro da gente".

O termo periferia denotaria, então, uma série de situações e conjunturas: determinada realidade socioespacial, uma inscrição étnico-racial e/ou de classe, uma referência à atuação político-cultural, mas também sentidos de pertença, afetividade e identificação baseados nas memórias, em uma estrutura de sentimento, para lembrar Williams (1977), que é compartilhada por certo agrupamento, em que a espacialidade assume centralidade na produção simbólica.

Então, quando afirmo que as representações sobre as periferias urbanas vêm se alterando em função da literatura marginal, já que seus agentes adotam a rubrica para definirem sua produção e se identificarem coletivamente, quero remeter à forma como ela vem sendo versada em manifestações artísticas e performáticas, que não a pautam apenas pelo trinômio "violência, tráfico, miséria", mas a constituem como lugar de criação, difusão e consumo literário.

Estamos na rua, loco, estamos na favela, no campo, no bar, nos viadutos, e somos marginais, mas antes somos literatura; isso vocês podem negar, podem fechar os olhos, virarem as costas, mas, como já disse, continuaremos aqui, assim como o muro social invisível que divide este país (FERRÉz, 2005, p. 11).

Essa autoatribuição classificatória "marginal" põe em pauta, aliás, a própria posição ocupada pelo morador das periferias na cidade, o que se dá pela oposição a um "outro", não periférico, e também a um "centro". Põe-se em xeque, assim, o polo

"Human Migration and the Marginal Man", em 1928. Park abriu caminho para o desenvolvimento de uma corrente de estudos que, mais tarde, seria seguida por Everett Stonequist e outros, que fizeram do "homem marginal" um problema sociológico, pois era um indivíduo que se "supunha viver na margem de duas culturas", como os imigrantes, por exemplo. 
negativo do binômio "centro-periferia", bem como os fatores que demarcam o que é aceito como central e o que é tido como alijado do centro, limítrofe, na medida em que o marginal/periférico passa a ser visto não mais como lugar de carência ou o arrebalde distante do centro, mas, sobretudo, como sendo portador do novo, da transformação, de uma nova riqueza, de uma potência estética reveladora.

Esses autores marginais buscam inverter a conotação negativa, estereotipada e por vezes preconceituosa do termo marginal, ressignificando a apropriação indébita e transformando-a em motivo de orgulho. A força do negativo, sua positivação, adquire potência subjetivadora: o sujeito que se autodenomina, que se autorrepresenta, inverte o preconceito que anteriormente o rebaixara. Como diz Penna (2015, p. 62): "marginal não é mais alegoria brasileira, mas máquina de guerra contra o Brasil que o marginalizara e diagnóstico do modo brasileiro de marginalizar".

Um dos mecanismos utilizados por esses agentes da cultura periférica é, portanto, o da positivação do negativo ou, como preferem Silvano Santiago (2004) e Rejane Pivetta (2011), a "afirmação cultural" dentro mesmo do sistema que os exclui. O poema "Faculdade", de Fuzzil (2010), reflete um pouco essa dialética autoafirmativa, quando proclama:

\author{
Minha faculdade é a rua! \\ Formei-me em Letras, \\ História e Geografia. \\ Fiz letra de samba, \\ Fiz letra de rap, \\ Letra de forma, \\ Letra de mão, \\ Letra de pixo, \\ Letra de grafite. \\ Fiz histórias nas ruas! \\ Contei histórias de vida, \\ Histórias de manos e de minas, \\ Histórias do cotidiano... \\ Histórias de miliano, \\ Histórias verídicas. \\ Andei pelos guetos, pelos becos, \\ Observei os terrenos baldios, \\ Construí poemas de madeira, \\ E barracos de papel. \\ Observei arranhas céus \\ E córregos poluídos. \\ Minha faculdade é a rua! \\ Formei-me em Letras, \\ História e Geografia.
}

Na intervenção poética de Fuzzil, nota-se um complexo processo de simbolização de uma vida que poderia ser considerada típica para pessoas oriundas e mo- 
radoras das periferias. A rua emerge quase como personagem, como espaço público, local físico-espacial e simbólico de sociabilidades, de convívio e afetividade, local de educação informal e de aprendizado. Os cursos de letras, história e geografia, por exemplo, tornam-se joguetes na imaginação do ator, porquanto denotam dois sentidos, um literal e outro conectado ao campo disciplinar. Com isso, o poeta visa dessacralizar e desmistificar o mundo acadêmico, propondo que o conhecimento é adquirido também na rua. $\mathrm{O}$ universo da cultura popular é trazido para dentro do texto poético, pois as "letras" são de samba e de rap, dois estilos que tradicionalmente estão ligados às favelas e periferias. O processo de alfabetização, por sua vez, entra em cena, começando pela "letra de forma" e passando à "letra de mão" - o que, talvez, remeta à alfabetização tardia do escritor. Mas, o caminho do letramento não segue aquele usual, o da educação formal, o da manifestação do discurso em locais tradicionais de produção e reprodução de saber, como a escola; mas o de uma "publicização" do ato de escrita, da intervenção urbana, ação que aparece na forma do grafite e do pixo - mais uma vez, a rua e a paisagem urbana são palcos privilegiados pelo autor.

No texto poético de Fuzzil, a rua adquire centralidade afetiva para a vida do poeta, e por isso ela é tão determinante para sua respectiva simbolização. Trata-se de um espaço urbano em que as "histórias" cotidianas são tecidas, a experiência é transmitida, e onde a fala e a vivência ocupam posição central na formação de um indivíduo, segundo o narrador, um "miliano". "Miliano", aqui, pode tanto ser uma corruptela de malandro e meliante, aquele que vive somente de "histórias verídicas", aquele cuja vivência se baseia em pequenas ilegalidades, como também um jargão para "mil anos", o que faria referência a algo ocorrido muito tempo atrás, tempo capaz de gerar saberes e experiências. É por meio do manuseio de recursos adquiridos na rua, na "geografia" crua das cidades, nas margens dos espaços institucionalizados - que ficam à margem, ou na margem entre o legal e o ilegal -, que o desenrolar de sua vida se torna possível.

E a explicação da necessidade desses atos ilícitos é a própria história de vida da personagem/poeta, muito ligada à paisagem urbana. Contudo, não se trata de qualquer cidade, mas de um espaço repleto de becos e vielas, um espaço forçosamente racializado, como são as periferias de São Paulo e de tantas outras cidades, feito de guetos, onde terrenos baldios, mais que metáforas do vazio e da improdutividade, da ausência, são locais dos possíveis, espaços de criação de poemas de madeira e barracos de papel, onde a literatura acaba sendo possibilitada, onde a simbolização e formalização da vida ocorre. Sua literatura é uma escrita essencial, porque textualiza seu espaço de vivência, o cenário e a realidade das periferias e dos marginais, os bairros desde onde ele pode ver os arranha-céus de um lado e os córregos poluídos do outro.

O poeta parece sintetizar uma leitura de mundo muito própria dos agentes que compõem o movimento marginal, que é o engajamento orgânico com as periferias urbanas, o ato de sair à rua, vivenciá-la, de tornar o espaço público uma escola. 
Essa afetividade com a rua é algo que já se iniciou com a cultura hip-hop, mas também com os grafiteiros, pixadores e demais artistas e interventores urbanos. Trata-se de colocar em prática um outro tipo de uso da rua e do espaço da cidade, diferente da lógica de mercantilização dos espaços públicos, lógica mais baseada no espírito de comunidade e associação, nas relações de afetividade com o lugar, cujo objetivo é o encontro, o entretenimento, a intervenção, que mexem no ritmo corrente da metrópole.

Entender a importância do espaço para esses agentes é entender como a representação ou a subjetivação do território remetem àquilo que Carlos Fortuna (2012) chamou, certa feita, de uma geografia emocional que transmite, ao espaço da cidade, uma enorme carga afetiva. É como se o território urbano, enquanto macroestrutura, fosse convertido em microespaços e passasse, então, a fazer parte efetiva dos agentes que o descrevem, como se passasse, de algum modo, a compor uma casa ou um habitat da experiência urbana subjetiva. O espaço não é só uma materialidade externa, temporânea e objetiva, palco para a expressão das identidades e para a consolidação das vivências pessoais, mas também território que pode ser internalizado, justamente porque envolve complexos processos de subjetivação constituído por novos enclaves e paisagens emocionais, ou seja, processos que impõem um novo regime de interesses, reivindicações, exigências, atuações e intervenções de cada grupo ou agente (ForTunA, 2012).

Há, ao que parece, um forte investimento desses novos agentes da cultura periférica em trazer para dentro da narrativa esse território afetivo da cidade, de subjetivá-lo de alguma forma, de "presentificá-lo", digamos, o que traduz uma maneira diversa de enunciar a periferia e, por essa via, uma outra estratégia de autoenunciar a si próprios. Esse processo de textualização da cidade e dos agentes que a vivenciam, por assim dizer, seria uma tentativa de representá-la como espaço dos possíveis, do novo, já que "estar na margem", como bem disse Bell Hooks (1990, p. 153), significa ocupar "um lugar de criatividade [...] a partir do qual se constrói um outro sentido do mundo". Pensar o mundo de outra forma, com base na experiência urbana e na ressignificação de uma história até então excluída das narrativas literárias, é criar uma experiência estética a partir da experiência urbana, algo próximo do que os artistas do hip-hop fizeram ao propor o quinto elemento, o conhecimento, essencial para a formação identitária, étnica e racial dos agentes, sobretudo em um contexto populacional negro, pobre e periférico.

\section{O recurso da "presentificação" da realidade periférica}

A literatura marginal é a que fala da periferia e, também, a que vem da periferia. A rubrica marginal é reivindicada, desde o início, pelos próprios escritores que compõem o corpo do movimento. Contudo, esses novos escritores falam, também, para indivíduos que habitam os mesmos espaços sociais e compartilham trajetórias similares de vida, o que fica evidente quando se observam as temáticas 
abordadas nas crônicas, romances, contos e, sobretudo, nas poesias, que sempre estabelecem aproximações e identificações com a realidade social na qual autor e leitor estão inseridos: violência policial, sexo, pobreza, política, lutas sociais, desigualdade, desemprego e racismo são assuntos caros a essa produção estética.

Tais temáticas sugerem que os agentes marginais têm buscado moldar uma tessitura diversa para a cidade, não se revelando condescendentes com a situação posta, não retratando a periferia apenas como local de reconciliação; ao contrário, afirmam a tensão e a contradição presentes na vida urbana, como o faz a poesia "Pendurados", de Marco Pezão (2013, p. 55):

Quem é você, operário

Que antes do clarão do sol espera o buso

Pra te levar enlatado, mordido

Pra mais um dia de trampo

Proporcionar a riqueza do patrão.

Quem é você, irmão

Que cheirando à cachaça

Bafo de rango mal nutrido

Volta nessa lotação

Se entregando, se encoxando

Querendo um aconchego

Ou um prato quente

Depois de dar o sangue, que já é pouco

A quem só faz engordar.

Barra, meu chapa

É foda, chegado

Que chances temos

$\mathrm{Na}$ aventura da vida?

Quem é da periferia

Tá ao redor feito bigode

Perto da boca, mas sempre por fora.

A condição de trabalhador - que mora longe do serviço, longe do centro, portanto -, a longa viagem de ônibus de volta para o lar - trajeto que faz, quase sempre, de forma espremida dentro de ônibus, trens e metrôs lotados -, toda essa rotina, pontuada algumas vezes pela bebida, pelos desejos de "aventuras na vida", pela comida e pelo desgaste do dia a dia, estão presentes no texto de Marco Pezão. Essa poesia coloca a cidade e a realidade social das periferias não apenas como pano de fundo, mas como fator da própria construção literária. E assim o faz por via de um humor crítico, mas também explicitando as contradições de sua própria realidade.

Visando abordar violência cotidiana e criação literária, ou melhor, reorganizando a paisagem das periferias, mediante a experiência urbana, na produção literária, a partir de uma experiência estética, muitos poetas vêm surgindo, engaja- 
dos e bem-dispostos a construir outras perspectivas para interpelar e interpretar a cidade e suas condições e contradições:

Ladeiras ásperas, esquinas em carne viva

Coração-tambor onde os caras-pálidas não ousam pisar

Poças acumulando ácidos serenos alaranjados

E trombetas apocalípticas do fun(k)anhão

Anunciam ninhadas de fiéis emergindo em cânticos evangélicos

Belezas televisivas e nigerianos de aço

SP, (S)elva de (P)edras (preciosas)

E não se engane não, seu moço

Que por aqui é tudo assim mesmo: esta zona, este alvoroço

$\mathrm{Na}$ virada tem até corrida pedestre

Uma tal de São Silvestre, com largada no ano novo

É desse jeitinho, velozes e furiosos, que a gente corre o ano todo

Uma lira paulistana endiabrada esquentando a chapa

Paulicéia Desvairada, Piratininga, punga, uma pinga

E a letra fugindo do salão elitista, nua, correndo pra rua

É baticum. É reza, É gíria [...] Danziger (2012, p. 64-65).

Esse poema, intitulado "Eles não usam Black Power", mostra que as esquinas, os botecos, a rua, as músicas, os eventos frequentes da cidade são questões que atravessam a vida cotidiana e a trajetória dos agentes, bem como sua poesia, cheia de gíria, na forma de reza. A oralidade do poema, muito pautada pelo ritmo do rap, é fundamental, pois finca seu pertencimento em uma forma literária específica (talvez, legatária do modernismo, mas fugindo de seus salões elitistas e bem vestidos) e coloca, de novo, a cidade como problema. O imaginário que perpassa o texto é notadamente urbano, pois emerge de um território concreto de São Paulo, de onde o escritor retira a matéria bruta para a criação poética e o recupera, dentro do espaço narrativo, como agente no processo de construção identitária (CoRONEL, 2013).

Nesse sentido, parece haver uma disposição, por parte desses novos escritores que despontam na cena literária brasileira, de figurar a realidade que os circunda por meio de formas idiossincráticas de expressão, ressignificação, ficcionalização e desestigmatização de periferias urbanas. $\mathrm{O}$ espaço social adquire centralidade literária ao ponto de formatar a dimensão temática da proposta estética do movimento marginal. A experiência urbana, que acaba por suscitar uma experiência estética, revela que as práticas literárias, os modos de organização empreendidos por agentes da cultura periférica, os saberes locais e as expressividades literárias provocados no cerne do movimento não podem ser apartadas da presença espacial. O poeta e cineasta Akins Kintê, em sua apresentação biográfica, alia trajetória de vida a uma visão bastante particular e metafórica que carrega sobre as periferias urbanas, dizendo:

Akins Kintê é poetinha sem tempo, remetido ao passado, presente e futuro, nascido no berço do skindô e criado nos terreiros do ziriguiduns. 
Tem como escola os campos de várzea. O corpo batuca sob a luz da lua e delicia os lábios na menina que traz na pele a mesma cor da noite. Bebe de se embriaga na fonte do samba e na oralidade dos negos velhos; bom com a memória, que é elo na manutenção na casa da ancestralidade [...]. Teu escritório é nas esquinas da vida, de onde silencia tuas mãos e o coração dedilha sempre um verso, seja lá qual for a adversidade da vida (KINTÊ, s. d.). ${ }^{9}$

Chama a atenção, novamente, a referência direta e positiva à periferia, à rua, às esquinas, como locais onde se vive e dos quais se erige o saber do eu enunciador, altivo com a memória de sua ancestralidade e muito à vontade com os elementos que o cercam, que lhe são familiares. Coloca-se em prática, mais uma vez, um processo de desestigmatização do espaço periférico. Ali, estão presentes tradições africanas, oralidade, campos de várzea, bares de samba, carnaval e uma presença quase idílica da população negra nas preferias, que atribui novos significados ao passado, presente e futuro, uma nova leitura da história, alterando, com efeito, formas de viver, de fazer e de dar significado à cidade e ao mundo das relações afetivas.

A periferia é lugar de criatividade e protagonismo, de sensibilidade e produção. O autor marginal, por sua vez, é objeto e sujeito da escrita que ele próprio propõe, testemunha de uma experiência e, ao mesmo tempo, "autoridade", no momento da representação mimética, de uma realidade periférica que aparece na escrita por conta de uma espécie de "presentificação" - que é mecanismo que transmuta experiência em literalidade..$^{10}$ A "presentificação" traz para dentro do texto poético experiências diversas de seus agentes, do passado e do presente, o que fica evidente no uso de um léxico idiomático peculiar, que inclui termos como "periferia", "margem", "gueto", "viela", "quilombo", "favela", a fim de entender variados tipos de situações.

Nos textos e recitações, metáforas, prosopopeias, anáforas e uma diversidade ampla de jogos de linguagem são desfiadas pelos poetas, o que indica consonância entre eles em termos de recursos, algo em comum na tentativa de retratar, representar e problematizar sua realidade.

Hoje eu viela

E ela mudou bastante

9 Este e outros textos do poeta estão disponíveis em seu blog: < akinskinte.blogspot.com.br/>.

10 Para Williams (1977), o processo de "presentificação" constituiria a formalização de relações específicas a certo grupo. Evaristo (2009, p. 19-20) segue na mesma toada: "Ciente de que a literatura não pode ser considerada fiel retrato da sociedade em que é produzida, não se pode afirmar, entretanto, que o discurso literário nasce e circula imune e impune ao meio onde foi criado. No ato criativo de imitação da vida, no movimento de discordância e/ou de concordância com a existência que lhe é consentida, ou com aquela que a sua percepção lhe permite alcançar, o escritor acaba por colocar no texto sinais reveladores da constituição de uma sociedade em certo momento histórico. Sinais esses que, como marcas textuais, podem ser capturados nas linhas e entrelinhas dos textos". 
[...] Viela acolhendo

Os que nada têm, nem a ninguém

Viela dando abrigo

Pra sonho de vida melhor

Na esquina, há perigo

Mas já viela pior.

Viela desrespeitada

Como se fosse nada

Até as tia enquadrada

Só por ser favelada Viela discriminada

Viela calada, viela lavada

De sangue na fita dada.

[...] Viela em barricada

Pela morte d'uma filha

Viela executada

Por organizada quadrilha

Viela em chamas

Debaixo de tiro e gás [...].

Depois disso

Ainda viela mais forte que antes

Mesmo com filhos difamados como meliantes

Viela ser reconstruída por vizinhos

Viela mais unida

Pois não estamos mais sozinhos.

[...] Viela marginalizada

[...] Viela criminalizada

[...] Por que ela é suspeita?

Será por viver a vida em perspectiva estreita?

[...] Quando eu a vi

Não foi amor ao primeiro olhar

$\mathrm{Eu}$ a achava feia, constrangedora, vulgar

Hoje, eu entendo ela

$\mathrm{E}$ a gente que vive nela

Que como eu não tem vergonha em dizer

É nóis favela! (SHABAZZ, 2015b)

Para além das aliterações, Shabazz faz menção ao território de origem, combinando denúncia sobre as condições sociais da população negra e periférica do Brasil com uma abordagem pautada na memória. Viela, claro, alude à rua estreita das periferias das cidades, estigmatizada, desrespeitada pelo senso comum, sem saída, ocupada, escura, desamparada, cheia de lodo, sempre considerada suspeita. O texto é um olhar voltado para espaços marginalizados de São Paulo, recolhendo memórias, fatos, estigmas e organizando-os. Porém, o que chama mais a atenção no poema "Eu Viela" é, novamente, o movimento de autoafirmação do espaço, da vida na periferia, da viela de pedrinhas cintilantes à qual o autor remete no início do poema, com crianças que correm por ela, contentes; a viela que acolhe os que nada têm, que dá abrigo, que se solidariza com o próximo. A forma urbana aparece no texto a partir do ritmo e de um movimento de valorização da favela e do 
grupo que a habita, mais unida que nunca; viela que é comunidade, mais forte que antes; viela que supera a violência; viela que é sempre renovada pelos vizinhos, que a compreendem e não têm vergonha de dizer: "É nóis, favela!".

Artifício semelhante é utilizado pela poeta Elizandra Souza (2012, p. 95), em seu soneto "Favela, mulher!", no qual há uma tentativa da poeta de autoafirmar a questão do espaço periférico, mas a partir de uma representação que é, ao mesmo tempo, coletiva e feminina:

\author{
Favela, mulher corajosa! \\ Nem criança, nem idosa \\ Nas mãos, flores e lanças \\ No olhar, a constante esperança. \\ Favela, mulher maravilhosa! \\ Nem arrogante, nem orgulhosa \\ Muitas vezes, parceira na dança \\ Outras, solitária nas andanças. \\ Nas escadarias de tua geografia \\ Correndo, feito menina \\ Seu sorriso espada que desafia. \\ No coração passou parafina \\ Abraça o caráter que não desfia \\ Já a face, encharcou de purpurina.
}

Favela é substância feminina, a partir da qual se inscreve a história passada e presente de inúmeras mulheres. A favela tem gênero, mas não tem idade, ela é criança, atual, mas ela é idosa, ancestral. É local de esperança e de orgulho; às vezes, violenta, com a lança nas mãos, mas outras vezes local de conciliação, com flores e emanando um horizonte de expectativas. A favela é uma geografia, às vezes isolada, solitária, outras vezes solidária, unida. Segundo Patrocínio (2013), o labor literário de Dugueto Shabazz, assim como também o de Elizandra Souza, é ressonância da dimensão política e territorial formada pelo discurso do rap e pelo legado do movimento negro; é a versão escrita e declamada, tornada objeto literário, de uma série de elementos urbanos presentes na realidade de seus autores, que textualizam e "presentificam" esses elementos, a fim de tornar o espaço periférico mais inteligível para seus moradores. A literatura e, em especial, a poesia são utilizadas como veículos para a estruturação de um discurso que recolhe histórias e memórias de uma realidade que é dura, mas repleta de afetividade, e cuja força está na forma, mas também na proposta de denunciar o estado corrente das coisas com uma perspectiva histórica do passado, "de antigamente", mas também com os olhos no presente -, sempre mantendo em vista um horizonte de expectativas e esperanças para o futuro. Trata-se, também, de manipular o objeto literário como estratégia para esclarecer os próprios pares e de alertar leitores/espectadores sobre alguns mecanismos de marginalização, de uma máquina urbana que suga, cada vez mais, os jovens negros e periféricos para suas engrenagens. 
Eu diria que, de modo geral, os espaços urbanos periféricos são transformados em recursos nas ações de seus agentes, na medida em que eles manejam palavras, símbolos, gírias e códigos diversos, bem como artefatos que lhes estão disponíveis, para produzir enunciados e comunicar-se com os outros, a fim de reivindicar espaços de fala, escrita, ação e atuação. A arte torna-se, nessa medida, uma práxis, uma experiência compartilhada, uma forma de vivenciar e pensar a cidade que a comporta e que a circunda. Abre-se, aqui, como percebeu Brandão (2013, p. 72), uma via para considerar a literatura, simultaneamente, como realidade, processo de ficção e movimento do imaginário dos agentes que a produzem. É uma realidade, porque produz e consolida relações sociais várias, inclusive urbanas, na forma do texto. Ela é também o processo por intermédio do qual a realidade nas periferias se corporifica, se "presentifica" e se textualiza, e que, a partir da indeterminação do imaginário coletivo, faz com que a realidade dos bairros pobres de São Paulo ganhe algum nível de determinação.

\section{Considerações finais}

A literatura que pulsa nas periferias paulistanas vem constituindo uma expressão artístico-literária performática, musicalizada, oral e política, o que apresenta sua novidade e, também, o caráter problemático que define sua própria especificidade: surge e se movimenta em um espaço no qual vão se embaralhar, sem muitas preocupações com distinções formais, uma vontade documental e sua contiguidade com um realismo perscrutador - com um intenso trabalho sobre a memória - e a consequente ficcionalização poética de experiências urbanas.

Essa especificidade estética tem a ver com feitios extraliterários. Em uma conferência proferida há cerca de 30 anos, o crítico João Alexandre Barbosa (1988) explicou que, à medida que a experiência literária vai se alargando por meio de outras experiências de cunho social, como a experiência urbana, por exemplo, também vai ficando mais evidente um paradoxo fundamental que constitui o objeto literário contemporâneo: o que se lê no texto é sempre mais do que apenas literatura; ou melhor, entre o que se diz, de onde se diz e o modo pelo qual se diz há um descompasso, uma intenção, um discurso subjacente, algo que serve de gatilho e de orientação para a existência daquela literatura.

Alguns pesquisadores acreditam que a imaginação literária das últimas décadas no Brasil, o discurso subjacente à produção literária contemporânea, tem sido predominantemente urbano. Segundo Pellegrini (2014), essa imaginação que vem sendo formatada conjuntamente com alguns processos sociais de cunho social e econômico, consequências da "guetificação" de algumas periferias ocorrida nas últimas décadas, propiciou o surgimento de agrupamentos com registros, propostas e dicções próprias, correspondente à emergência de novas subjetividades nas bordas geográficas e simbólicas da sociedade brasileira. A presença do espaço e a vontade de documentar suas dinâmicas, muitas vezes problemáticas, é uma tenta- 
tiva de conferir uma maior fidedignidade ao que se narra. A estratégia utilizada parece ser a de reintroduzir um recurso literário na narrativa, que é uma visada realista e crítica do mundo e das relações sociais.

A necessidade de ficcionalizar poeticamente certas experiências urbanas, a partir do recurso da verossimilhança, é a disposição dessa produção periférica de "fabricar o sensível" (RANCIÈRE, 2005), a partir da vivência, vale dizer, a partir da matéria bruta da experiência urbana, de modo a constituir um mundo de afetos na própria narrativa que se propõe e, assim, partilhá-lo por intermédio de dois vetores constituintes: as ordenações narrativas da ficção e as ordenações da descrição e interpretação de fenômenos do mundo histórico e social. Trata-se da possibilidade estética de conservar - e, portanto, de salvar - os "laivos da vivência", de modo a transmiti-la em forma afetiva (ficcional ou não) aos que não a viveram, exercício que alimenta um desejo metonímico que há na representação como reapresentação de algum evento, período, situação, cenas que, caso contrário, se perderiam ou não encontrariam saída transmissível (VECCHI, 2010). Daí que a própria noção de experiência urbana aparece como sustentáculo importante desse tipo de experiência estética, responsável, para fazer uso de um léxico de Raymond Williams, por uma estruturação de sentimentos e pertencimentos de cada um a uma mesma prática empreendida nas periferias.

Os poetas valorizam a narração de situações que os acometem, pautando problemas sociais, de fundamento histórico, estimulando a criação, o consumo e a difusão literárias em circuitos descentrados da cidade. E a literatura marginal não satisfaz apenas a determinações literárias, formalísticas e temáticas, mas, sobretudo, políticas e sociais. Afinal, a principal reivindicação desse conjunto de experiências literárias, que preza um tipo novo de realismo - calcado na problematização do espaço periférico -, é a de que aos taxados historicamente como "excluídos" do fazer literário, ou então como marginais e periféricos da produção literária nacional, cabe construir os meios, as condições e os mecanismos próprios de desestigmatização do local onde vivem, bem como inventar formas de contornar processos de exclusão, trazendo-os para dentro de suas criações poéticas.

\section{Referências}

BArbosa, João A. Leituras: o intervalo da literatura. Linha D’Água, São Paulo, n. 5, p. 22-32, 1988.

BIn, Marco Antonio. As redes de escritura nas periferias de São Paulo: a palavra como manifestação de cidadania. Tese (Doutorado em Ciências Sociais) - Pontifícia Universidade Católica de São Paulo, São Paulo, 2009.

Binho. Antologia do Sarau do Binho. São Paulo: Sarau do Binho, 2013.

Brandão, Luís Alberto. Teorias do espaço literário.São Paulo: Perspectiva, 2013. 
CARrIL, Lourdes. Quilombo, favela e periferia. São Paulo: Annablume, 2006.

Ciríaco, Rodrigo. Pode pá que é nóis que tá. São Paulo: Um Por Todos, 2012.

Coronel, Luciana Paiva. A escrita da cidade partida. Estudos de Literatura Brasileira Contemporânea, Brasília, n. 42, p. 29-45, 2013.

Cunha, Euclides da. Os Sertões. São Paulo: Brasiliense, 1985.

DALCASTAGNÈ, Regina. A auto-representação de grupos marginalizados: tensões e estratégias na narrativa contemporânea. Letras de Hoje, Porto Alegre, v. 42, p.1831, 2007.

DANZIGER, Walner. Eles não usam Black Power. Rebosteio, São Paulo, n. 4, jul. 2012.

Eslava, Fernando. Literatura marginal: o assalto ao poder da escrita. Estudos de Literatura Brasileira Contemporânea, Brasília, n. 24, p. 35-51, 2004.

Evaristo, Conceição. Questão de pele para além da pele. In: Ruffato, Luiz. Questão de pele: contos sobre preconceito racial. Rio de Janeiro: Língua Geral, 2009.

FARIA, Alexandre Graça. Ginga e resistência na poesia de Allan da Rosa. Humanitae, Aracaju, v. 1, n. 1, p. 6-13, 2011.

Faria, Alexandre Graça; Penna, João Camillo; Patrocínio, Paulo R. Tonani (Org.). Modos da margem: figurações da marginalidade na literatura brasileira. Rio de Janeiro: Aeroplano, 2015.

FerRÉz. (Org.). Literatura marginal: talentos da escrita periférica. Rio de Janeiro: Agir, 2005.

Fortuna, Carlos. (Micro)territorialidades: metáfora dissidente do social. Revista Terra Plural, Ponta Grossa, v. 6, n. 2, p. 199-214, jul./dez. 2012.

Fórum de Cultura da Zona Leste. Manifesto Periférico: pela lei de fomento à periferia. Teatro de Rua e a Cidade, São Paulo, 3 jun. 2014. Blog. Disponível em: <https://goo.gl/E1Ty4H>. Acesso em: 2 out. 2016.

Fuzzil. Caturra. São Paulo: Elo da Corrente, 2010.

Hooks, Bell. Yearning: race, gender and cultural politics. Boston: South End, 1990.

Kintê, Akins. Akins Kintê. Blog pessoal. São Paulo, [S.d]. Disponível em: <http: //akinskinte.blogspot.com.br/>. Acesso em: $1^{\circ}$ mar. 2017.

LeITe, Eleilson. Mesmo céu, mesmo CEP: produção literária na periferia de São Paulo. Dissertação (Mestrado em Filosofia) - Universidade de São Paulo, São Paulo, 2014.

Nascimento, Erica Peçanha do. É tudo nosso! Produção cultural na periferia paulistana. Tese (Doutorado em Antropologia Social) - Universidade de São Paulo, São Paulo, 2011. 
Nascimento, Erica Peçanha do. Vozes marginais na literatura. Rio de Janeiro: Aeroplano, 2009.

Oliveira, Lucas Amaral de. Speaking for themselves: observations on a "marginal" tradition in Brazilian Literature. Brasiliana - fournal for Brazilian Studies, v. 5, n. 1, p. 441-471, 2016.

Oliven, Ruben George. Marginalidade urbana na América Latina: aspectos econômicos, políticos e culturais. In: Oliven, Ruben George. Urbanização e mudança social no Brasil. On-line. Rio de Janeiro: Centro Edelstein, 201o.Disponível em: $<\mathrm{http}$ ///books.scielo.org/id/z439n>. Acesso em: $1^{\circ}$ mar. 2017.

Patrocínio, Paulo R. Tonani. A volta da realidade das margens. Estudos de Literatura Brasileira Contemporânea, Brasília, n. 39, jan./jun., p. 57-75, 2012.

Patrocínio, Paulo R. Tonani. Escritos à margem. Rio de Janeiro: 7 Letras, 2013.

Pellegrini, Tânia. Moda importada: introdução do realismo no Brasil. Itinerários, Araraquara, n. 39, p. 117-138, jul./dez. 2014

Penna, João Camillo. Margem entrevista. In: Tennina, Lucía et al. (Org.) Polifonias marginais. Rio de Janeiro: Aeroplano, 2015.

Pezão, Marco. Nóis é ponte e atravessa qualquer rio. São Paulo: Reza Brava, 2013.

Pivetta, Rejane. Literatura marginal: questionamentos à teoria literária. Ipotesi, Juiz de Fora, v. 15, n. 2, esp., p. 31-39, jul./dez. 2011.

QuEIroz, Doralice Alves de. Mulheres cordelistas: percepções do universo feminino no cordel. In: Seminário Nacional Mulher e Literatura, 11., e Seminário Internacional Mulher e Literatura, 2., Rio de Janeiro, 2 a 5 ago. 2005. Anais... Rio de Janeiro: ANPOLL, 2005.

RANCIÈre, Jacques. A partilha do sensível: estética e política. São Paulo: 34, 2005.

ReYes, Alejandro. Vozes do porão: a literatura periférica/marginal do Brasil. Rio de Janeiro: Aeroplano, 2013.

SAlom, Júlio Souto. Combater a subcidadania disputando o jogo literário: uma contribuição ao estudo da literatura marginal-periférica. Dissertação (Mestrado em Sociologia) - Universidade Federal do Rio Grande do Sul, Porto Alegre, 2014.

Santiago, Silvano. O cosmopolitismo do pobre. Belo Horizonte: Editora da UFMG, 2004 .

Shabazz, Dugueto. Notícias jugulares. São Paulo: Toró, 2006.

Shabazz, Dugueto. Aos flancos e barrancos. 2015a. (3m13s). Disponível em: <https: goo.gl/GMGjd $3>$. Acesso em: o9 nov. 2017.

Shabazz, Dugheto. Eu Viela. 2015b. (4m4os). Disponível em: <https:goo.gl/ Sxsku4 >. Acesso em: 11 set. 2015. 
Silva, Rogério de Souza. A periferia pede passagem: trajetória social e intelectual de Mano Brown. Tese (Doutorado em Sociologia) - Universidade Estadual de Campinas, Campinas, 2012.

Silva, José Carlos Gomes da. Literatura negra: memória viva. Texto produzido para o curso de extensão Cultura Afro-Brasileira: Fundamentos para a Prática Pedagógica, realizado na Universidade Federal de São Paulo, Unidade Santo Amaro, maio/jul. 2013.

Silva, Mário Augusto Medeiros da. A descoberta do insólito: literatura negra e literatura periférica no Brasil (1960-200o). Rio de Janeiro: Aeroplano, 2013.

SouzA, Elizandra. Águas da cabaça. São Paulo: Mjiba, 2012.

Teixeiro, Alva Martínez. A plenitude de um vazio em que a pobreza não é mais paisagem: a periferia em Paulo Lins e Ferréz. Estudos de Literatura Brasileira Contemporânea, Brasília, n. 41, p. 61-86, 2013.

Tennina, Lucía et al. (Org.) Polifonias marginais. Rio de Janeiro: Aeroplano, 2015.

Tennina, Lucía. Cuidado com os poetas! Literatura e periferia na cidade de São Paulo. Porto Alegre: Zouk, 2017.

VeCCHI, Roberto. A memória poética como patrimônio de sofrimento. In: CAVALHEIRO, Juciane (Org.). Literatura, interfaces, fronteiras. Manaus: Editora da UEA, 2010 .

WACQUANT, Loïc. Gueto, banlieue, favela: ferramentas para se repensar a marginalidade urbana. In: Encontro AnUAl dA Associação Nacional de PósGraduação e Pesquisa em Ciências Sociais, 25., Caxambu, 16 a 20 out. 2001. Anais... São Paulo: ANPOCS, 20o1. Disponível em: <https://goo.gl/Bf1Qjd>. Acesso em: 30 out. 2017.

Williams, Raymond. Marxism and literature. Oxford: Oxford University Press, 1977 .

Recebido em 7 de outubro de 2017.

Aprovado em 24 de março de 2018.

\section{Resumo/Abstract/Resumen}

Experiência literária e experiência urbana: notas sobre a literatura marginal

Lucas Amaral de Oliveira 
Nos últimos anos, tem sido possível observar a projeção de escritores das periferias paulistanas na cena literária contemporânea. Esses agentes da chamada "cultura periférica" têm se mostrado hábeis em trazer a questão urbana e seus reveses sociais e raciais para dentro da narrativa. Mas quais os recursos investidos nas práticas literárias desses escritores engajados em impulsionar sua produção, divulgação e consumo nas periferias de São Paulo? A proposta deste artigo é analisar a incidência de experiências urbanas variadas no labor literário e na produção poética de escritores que se reconhecem como integrantes do movimento da literatura marginal, verificando em que medida se pode atrelar experiência literária, representação do espaço e participação artístico-comunitária dentro desse fenômeno cultural ainda em curso.

Palavras-chave: literatura marginal, cidade, periferias urbanas, experiência.

\section{Literary and Urban Experience: observations of Brazilian Marginal Lite- rature}

\section{Lucas Amaral de Oliveira}

In the last few years, it has been possible to observe the projection of writers from urban peripheries into the Brazilian literary scene. These literary agents of the socalled "peripheral culture" have been quite skilled in bringing the urban question and its social and racial setbacks into the narrative. However, what do these writers use as resources to boost the production, circulation and consumption of literary goods over São Paulo urban outskirts? The aim is to analyze the incidence of a multitude of urban experiences into the literary work of marginal writers from the outskirts of São Paulo, with the objective of understanding the extent to which one can link literary creation, representation of space, and artistic participation.

Keywords: marginal literature, city, urban peripheries, experience.

\section{Experiencia literaria y experiencia urbana: notas sobre la literatura mar- ginal}

\section{Lucas Amaral de Oliveira}

En los últimos años se ha podido observar la emergencia de escritores de las periferias urbanas en la escena literaria brasileña. Estes agentes literarios de la llamada "cultura periférica"se han mostrado bastante hábiles a la hora de llevar las cuestiones urbanas y sus reveses sociales y raciales hacia el interior de la narrativa. Pero ¿cuáles son los recursos formales y temáticos utilizados en las prácticas literarias de estes agentes comprometidos en impulsar su producción, divulgación y consumo? Para ello, examino la incidencia de diversas experiencias urbanas en el trabajo literario y en la producción textual de escritores que se recono- 
cen como integrantes del movimiento de la literatura marginal de São Paulo, buscando comprender en qué medida se pueden vincular creación literaria, representación del espacio y participación artístico-comunitaria dentro de este fenómeno cultural en curso.

Palabras clave: literatura marginal, ciudad, periferias urbanas, experiencia. 